\title{
Elemental and morphological analysis of enamel following the application of two bleaching systems with amorphous calcium phosphate: effect on enamel erosion susceptibility
}

\author{
Shaymaa M. Nagi ${ }^{*} \mathbb{B}$, Shahinaz H. Nabil ${ }^{1}$ and Mohamed H. Zaazou ${ }^{2}$
}

\begin{abstract}
Background: Using remineralizing agents during and after bleaching procedures could maintain enamel surface, decreasing its erosive susceptibility. This study evaluated the efficacy of an in-office and at-home bleaching materials with amorphous calcium phosphate (ACP) on the susceptibility of the enamel to erosion. Forty-five bovine specimens were separated into three groups. Group A: no bleaching (control). Group B: Zoom 2 bleaching followed by ACP application. Group C: Nite White ACP. All specimens in all groups were subjected to an erosive challenge for five days. Using Energy Dispersive X-ray all specimens were subjected to elemental analysis and were examined for morphological changes under Scanning Electron Microscope (SEM).

Results: Group B showed the highest mean calcium, phosphorus and sodium weight percent (wt\%). Both Groups B and $C$ showed statistically significant difference. While, there was no statistically significant difference between both Groups A and B.The sodium mean wt\% showed a statistically significant difference in all groups. The magnesium mean wt\% showed no statistically significant difference in all groups. SEM photomicrograph revealed hollowing of prism cores with intact prisms peripheries for group A. Group B showed relativity smooth surface with minor pores, while Group C showed an increase in the depth of surface irregularities and depressions.
\end{abstract}

Conclusions: Enamel susceptibility to erosion after bleaching procedure was material dependent. Zoom 2 bleaching agent followed by ACP application did not increase the susceptibility of the enamel surface to erosion. Adding ACP to Nite White bleaching agent had no benefit on reducing enamel susceptibility to erosion.

Keywords: Enamel erosion, Demineralization, Bleaching, Amorphous calcium phosphate, Acidic challenge

\section{Background}

In the recent years, teeth bleaching popularity has dramatically been grown, also was estimated that it could be performed in the dental office on more than one million

\footnotetext{
*Correspondence: smnagi@gmail.com

${ }^{1}$ Restorative and Dental Materials Department, Oral and Dental Research Division, National Research Centre, 33 El Bohouth st. (former El Tahrir st.), P.O.12622, Dokki, Giza, Egypt

Full list of author information is available at the end of the article
}

patients. Teeth bleaching has been known as being effectual, safe, as well as a minimally invasive and a nondestroyable treatment. There are a variety of methods that comprise different bleaching materials having many different concentrations, periods of applications, mode of application as well as the light activation (Cakir et al. 2012).

The action of bleaching mechanism mainly depends on an oxidation complex reaction that releases responsive 
oxygen species that infiltrate via the enamel pores and break down the large organic molecules producing smaller lighter compounds. Although bleaching procedures have been reported to be safe and non-destructive, several studies demonstrated several side effects resulted from teeth whitening such as changes in the mineral content of the enamel teeth (Moreire et al. 2017).

It has been stated that using remineralizing agents following bleaching treatments could minimize the adverse effects resulted from bleaching procedure. Moreover, remineralizing agents were added by the manufacturers to the bleaching gel formulations targeting to preserve the tooth enamel hardness and to lower its sensitivity. Amorphous calcium phosphate has been widely used by the dentists and was positively associated with the caries inhibition. Amorphous calcium phosphate releases both calcium and phosphate ions, hence it maintains a mineral environment which is supersaturated by enhancing enamel remineralization and reducing its demineralization (Oldonini et al. 2018).

The association between the alteration of the bleached surface enamel with its susceptibility to erosion that could result from the communication between the demineralizing solution and the bleached enamel was discussed. In a previous study, performing at home bleaching technique did not cause the enamel to be susceptible to erosive lesions (Engle et al. 2010). In another study, the applying carbamide peroxide bleaching material caused the enamel to be more prone to erosion. Considering the addition of bleaching agents with higher peroxide concentrations could higher the enamel susceptibility to erosive lesions could be beneficial to prevent enamel demineralization (Chen et al. 2008).

Therefore, studying the impact of amorphous calcium phosphate remineralizing agent with both in-office and at home bleaching materials on the enamel susceptibility to erosive lesions might be of great value. The null hypothesis investigated were that (1) Both In-office and at-home bleaching agents do not higher the enamel liability to erosive lesions. (2) There is no change in the erosion susceptibility of the surface enamel when treated with inoffice bleaching agent followed by ACP application in a separate step compared to enamel treated with at home bleaching agent with ACP remineralizing gel incorporated in it.

\section{Methods}

\section{Materials used in this study}

Hydrogen peroxide photo-activated in-office bleaching material and one carbamide peroxide at-home chemically- activated bleaching agent were tested in this study. Also, Amorphous calcium phosphate relief gel was utilized. Materials name, composition and manufacturers are represented in Table 1.

\section{Teeth selection and specimens' preparation}

Forty-five sound incisors of bovine teeth were selected and used in this study. Teeth were ultrasonically scaled to be cleaned from deposits then under running water they were washed for removing any debris or remaining tissues (Whang and Shin 2015). Roots of the specimens were cut using double-sided cutting disc (Dental Golden S.A.W., Switzerland) $2 \mathrm{~mm}$ under the cemento-enamel junction. Endodontic file was then used to remove the pulp tissues from all specimens. An acid resistant varnish (Nail polish, Barielle, NY, USA) was coated on the incisal and cervical two thirds of the labial surfaces of the crowns, leaving the middle one third uncovered with the nail varnish. Following setting of the nail varnish, specimens were labelled from the palatal surface for better identification. All prepared samples were stored in an artificial saliva for one week before any treatment to mimic the oral environmental condition. Artificial saliva formula was [(moles/L): $\left(\mathrm{CaCl}_{2}(0.7), \mathrm{MgCl}_{2} \cdot 6 \mathrm{H}_{2} \mathrm{O}(0.2)\right.$, $\mathrm{KH}_{2} \mathrm{PO}_{4}$ (4.0), $\mathrm{KC} 1$ (30), $\mathrm{NaN}_{3}$ (0.3), HEPES buffer (20)] $(\mathrm{PH}=7)$ (Pashley et al. 2004).

Table 1 Materials name, composition and manufacturers

\begin{tabular}{|c|c|c|}
\hline Product & Composition (w/w) & Manufacturer \\
\hline $\begin{array}{l}\text { Zoom } 2 \text { (in- office } \\
\text { Photo-activated } \\
\text { bleaching agent) }\end{array}$ & 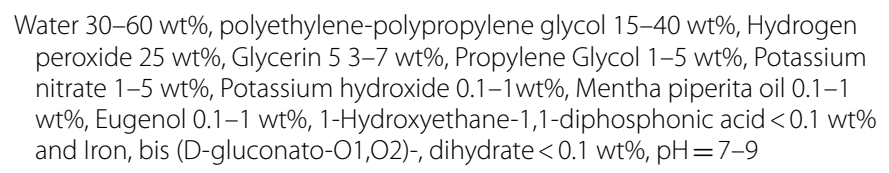 & Discuss Dental, Inc. Culver City, CA, 90232, USA \\
\hline $\begin{array}{l}\text { Nite white ACP (At- } \\
\text { home chemically } \\
\text { activated bleach- } \\
\text { ing agent) }\end{array}$ & $\begin{array}{l}\text { 22\% carbamide peroxide, Potassium nitrate, amorphous calcium phosphate } \\
\text { (ACP), } \mathrm{pH}=5.5\end{array}$ & Discuss Dental, Inc. Culver City, CA, 90232, USA \\
\hline Relief ACP gel & Amorphous calcium phosphate & Discuss Dental, Inc. Culver City, CA, 90232, USA \\
\hline
\end{tabular}




\section{Study design and specimens grouping}

The 45 enamel specimens were haphazardly separated into three groups of 15 specimens each.

Group A: specimens didn't receive bleaching treatment (control group),

Group B: specimens received Zoom 2 photo-activated in-office bleaching treatment, followed by ACP application.

Group C: specimens received Nite White chemically-activated at-home bleaching with ACP incorporated into it.

The R Foundation for Statistical Computing. In a oneway ANOVA study, the results revealed that the total specimen size of 15 specimens will be enough to detect a mean change between the study groups with a control of $80 \%$ and a two-sided meaning level of $5 \%$.

\section{Bleaching gel application}

Before bleaching procedure, specimens were brought out of the artificial saliva, then were air-dried for $5 \mathrm{~s}$ using oil free compressed air.

\section{Zoom 2 in- office bleaching application (Group B)}

Specimens assigned for this group received Zoom 2 bleaching gel on the exposed labial middle one third. According to the manufacturer's instructions Zoom 2 bleaching gel was applied in approximately $1 \mathrm{~mm}$ thickness, then Zoom 2 light (short-arc metal halide bulbwavelength of 365-500 nm) was adjusted to be directed towards the labial surface for a period of $15 \mathrm{~min}$. The gel was then removed using cotton rolls and specimens were then received another application of the bleaching gel. This technique was repetitive three times ending in a total time of $45 \mathrm{~min}$ bleaching time application. Specimens were then rinsed using air/water jet for standardized time of $1 \mathrm{~min}$ to remove the bleaching materials. After the completion of the bleaching procedure, According to the manufacturer instructions ACP relief gel was applied to the bleached area of the labial surfaces of the specimens and left for ten minutes. Finally, storage of specimens were performed in artificial saliva at $37^{\circ} \mathrm{C}$.

\section{Nite White ACP at-home bleaching application (Group C)} Specimens in Group $C$ received Nite White ACP bleaching gel. According to the manufacturer's instructions Nite White ACP bleaching gel was applied in approximately $1 \mathrm{~mm}$ thickness on the exposed labial middle one third twice per day (30 min each) for 2 weeks. Specimens were then rinsed using air/water jet for standardized time of $1 \mathrm{~min}$ for removal of the bleaching gel. Specimens were then stored in the artificial saliva at $37{ }^{\circ} \mathrm{C}$. This bleaching procedure was repeated daily for two weeks resulting in a total bleaching treatment of $14 \mathrm{~h}$.

\section{Erosive challenge}

All specimens in group A, B and C were exposed to the erosive challenges for a period of 5 days. The erosive cycles started by immersion of each specimens in $2 \mathrm{ml}$ of unstirred soft drink ( $\mathrm{pH}=3.2)$ (Sprite, Coca-Cola company, Germany) four times each day, for two minutes each. This was followed by a remineralization period for two hours between erosive challenges by immersion of each specimen in $20 \mathrm{~mL}$ of an unstirred artificial saliva, ( $\mathrm{pH} 7.0)$. All specimens were then stored in artificial saliva all the night. The beverage was replaced at the end of each challenge, and artificial saliva was renewed daily (Magalbaes et al. 2008).

\section{Elemental analysis}

After completion of the bleaching treatments, all specimens in groups $A$ and $B$ and $C$ were subjected to elemental analysis to assess the calcium (Ca), phosphorus (P), sodium $(\mathrm{Na})$, and magnesium $(\mathrm{Mg})$ ion levels of each specimen using non environmental energy dispersive $\mathrm{x}$-ray (EDX) analysis (Model Philips XL 30). Specimens were coated with a layer of carbon to change the electrical conductivity in a high vacuum evaporator. Specimens were placed over stumps that were placed inside a hollow having their labial surfaces beholding upwards. Three readings were taken from the middle one third of each specimen in three different regions, then their average was calculated.

\section{Surface morphology assessment}

Representative specimens have been observed under the scanning electron microscope (SEM) that was attached to the EDX, to evaluate the morphological changes. Representative photomicrographs for enamel specimens after erosive challenge, enamel surface bleached with Zoom 2 followed with ACP application then exposure to the erosive challenge, and enamel bleached with Nite White incorporated in it ACP then exposure to the erosive challenge were taken at magnification 1000X.

\section{Statistical analysis}

Mean and standard deviation values were calculated for each group. Data showed parametric distribution. Oneway ANOVA was used to show the difference between the tested groups followed by Tukey's (HSD) post hoc test for pairwise comparison. A value of $\alpha=0.05$ was used as the level for significance. Statistical analysis was 
performed with IBM SPSS Statistics for Windows, Version 23.0. Armonk, NY, USA.

\section{Results}

\section{Results of elemental analysis}

Table 2 showed mean, Standard deviation and results of ANOVA and Tukeys tests for the comparison between means weight percentage (wt\%) of calcium $(\mathrm{Ca})$, phosphorus $(\mathrm{P})$, sodium $(\mathrm{Na})$, magnesium $(\mathrm{Mg})$ ions in the control (unbleached), Zoom 2 followed by ACP and Nite white ACP, after exposure to erosive challenge. It was shown that there was no statistically significant difference in the mean calcium weight percent between the control and Zoom 2 groups. On the other hand, Nite white group that showed the lowest mean calcium wt\%. Zoom 2 group showed the highest mean phosphorus $w t \%$. There was statistically significant difference in the mean sodium weight percent between all groups. There was no statistically significant difference in the magnesium mean weight percent among all groups.

\section{Results of ultra-morphological analysis}

Photomicrographs of enamel surface after erosive challenge showed scooping of prism cores with moderately complete prims peripheral, looking like a honeycomb
(Fig. 1a). The enamel surface bleached with Zoom 2 followed with ACP application then exposure to the erosive challenge showed relativity smooth surface with minor pores, and with no visible evidence of etching and prism pattern appearance (Fig. 1b). On the other hand, enamel surface bleached with Nite White incorporated in it ACP, then exposure to the erosive challenge showed more morphologic surface alterations involving; removing the aprismatic layer, enlarged penetration of the enamel grooves, and irregular depressions of various depths could also be observed (Fig. 1c).

\section{Discussion}

In spite of the wide-spread use of bleaching techniques and systems, there was still confusion to the effect of bleaching application on the tooth surface. This confusion could be related to the usage of a variety of bleaching techniques, the unlike concentrations of the bleaching agents as well as the presence of different bleaching systems (Mielezarek et al. 2008).

Although teeth bleaching is believed to be a short-term therapy, it should not be a further threat for subjects susceptible to erosion. It might be speculated that after the bleached enamel surface is exposed to an acid, chemical changes might promote a higher spread of erosive agents

Table 2 Mean, standard deviation (SD) for elemental analysis weight percentage (wt\%) of different groups

\begin{tabular}{|c|c|c|c|c|c|c|c|}
\hline & \multicolumn{2}{|c|}{ Control (unbleached)(Group A) } & \multicolumn{2}{|c|}{ Zoom 2 followed by ACP (Group B) } & \multicolumn{2}{|c|}{ Nite white ACP (Group C) } & \multirow[t]{2}{*}{$p$ Value } \\
\hline & Mean & SD & Mean & $\mathrm{SD}$ & Mean & $\mathrm{SD}$ & \\
\hline $\mathrm{Ca}$ & $62.16^{\mathrm{a}}$ & 2.93 & $64.8^{\mathrm{a}}$ & 3.78 & $59.49^{b}$ & 4.2 & $<{ }^{*} 0.001$ \\
\hline$P$ & $30.03^{b}$ & 0.8 & $37.44^{\mathrm{a}}$ & 12.38 & $29.47^{b}$ & 1.99 & $<{ }^{*} 0.001$ \\
\hline $\mathrm{Na}$ & $4.77^{b}$ & 2.85 & $7.06^{\mathrm{a}}$ & 3.19 & $3.01^{c}$ & 1.96 & $<{ }^{*} 0.001$ \\
\hline $\mathrm{Mg}$ & 1 & 0.4 & 0.97 & 0.93 & 0.82 & 1.46 & $0.574 \mathrm{~ns}$ \\
\hline
\end{tabular}

Different letters in the same row mean significant differencêै $<0.0{ }^{*} .{ }^{*}$; significant $(p<0.05)$ ns; non-significant $(p>0.05)$

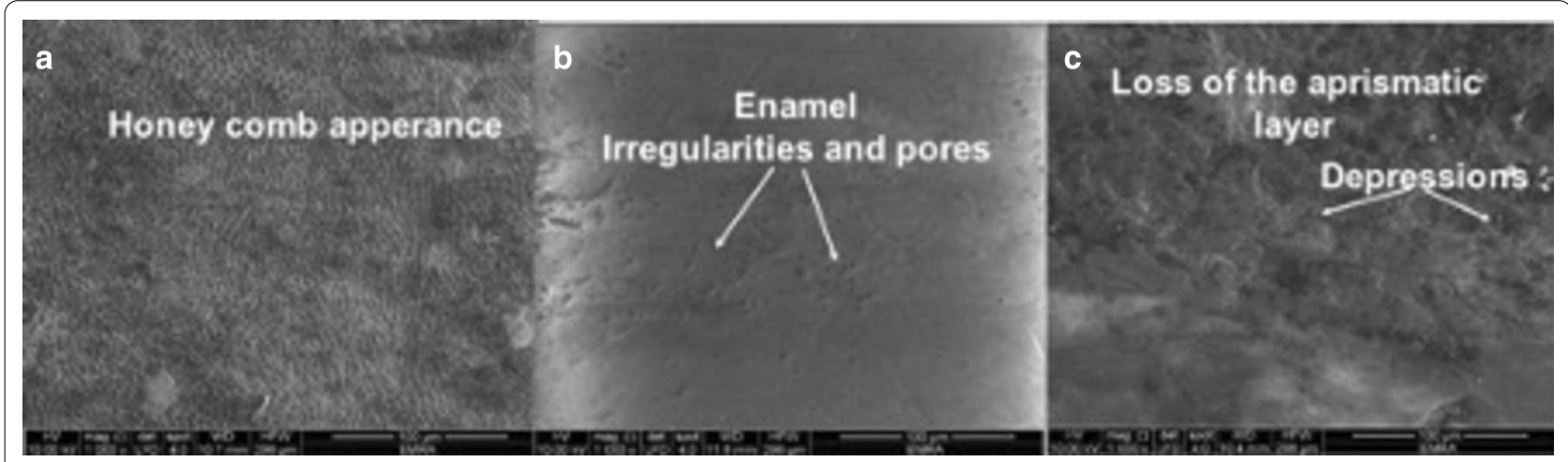

Fig. 1 SEM photomicrographs 1000x. a Control (enamel surface after erosive challenge, group A); b Enamel surface bleached with Zoom 2 followed with ACP application then exposure to the erosive challenge (group B); c Enamel bleached with Nite White ACP then exposure to the erosive challenge (group C) 
within the enamel surface resulting in a pronounced demineralization (Hegedus et al. 1999).

Bleaching is a process where hydrogen peroxide breaks down producing oxygen and per-hydroxyl free radicals that cause oxidation of the colored macro-sized molecules breaking them down into lighter and smaller colored molecules. These fragments penetrate the surface of the tooth causing the bleaching effect (Giannini 2013). Many studies stated that bleaching teeth alters the mineral content of the enamel surface (Santini et al. 2008; and El Fallah and Swan 2013). Therefore, using remineralizing agent to remineralize the bleached enamel either following the bleaching procedure (Chuang et al. 2009) or by incorporating calcium and phosphate ions to be in contact with the bleaching agent (De Vasconcelos et al. 2012) might be essential to provide a net mineral gain to the enamel surface.

Bovine teeth were selected and obtained to be used in the current study. The choice behind using bovine teeth was as they could be obtained easily in a non-carious form and in an acceptable good condition. According to Yamaguchi et al. (2006); and Attin et al. (2005) the chemical and physical properties of bovine teeth resemble the human teeth.

Elemental analysis was carried out using energy dispersive $\mathrm{x}$-ray analysis (EDX) which provides sensitive and accurate data. Energy dispersive $\mathrm{x}$-ray analysis is a noninvasive system that provides an absolute quantification of gain or loss of the minerals that might occur during or after completion of the bleaching procedure and exposure to the erosive challenge (Poomi et al. 2010).

In this study two different bleaching systems were tested: $25 \%$ hydrogen peroxide Zoom 2 in-office and 22\% carbamide peroxide Nite white ACP at-home bleaching system. Elemental analysis was assessed after exposing all the specimens in all groups (A, B \& C) to an acidic beverage. Results revealed that the exposure of $25 \%$ hydrogen peroxide bleached enamel (Zoom 2 in-office bleaching (group B)) to the acid beverage did not showed significant $\mathrm{Ca}$ and $\mathrm{P}$ wt\% change compared to the control (unbleached (group A)). While, Nite white ACP bleaching agent (group $C$ ) revealed a statistically significant decrease in the $\mathrm{Ca}$ and $\mathrm{P}$ wt\% related to the control and Zoom 2 bleached groups. Therefore, the first null hypothesis tested that in-office and at-home bleaching agents did not increase the susceptibility of the enamel surface to erosive challenges was partially rejected. As athome Nite white ACP increased the enamel susceptibility to erosion, while in-office Zoom 2 didn't.

Zoom 2 bleaching system comprised the application of amorphous calcium phosphate (ACP) relief gel following its application to the enamel surface. This protocol might have promoted and enhanced the remineralization process of the bleached enamel surface due to the deposition of ACP on the enamel surface that stabilizes the calcium phosphate and maintaining a supersaturation state, thus enhancing hard tissue remineralization (Poggio et al. 2016). Moveover, Zoom 2 bleaching agent is a photocatalytic bleaching system consisting of $25 \%$ hydrogen peroxide and photocatalytic catalyst. It consists of fenton type (iron salt) which when used with the ultraviolet light source, causes activation of the peroxide through the selfrenew process of the reaction of the photo-fenton. Utilizing the peroxide photo-fenton reaction plus the dissolved iron leads to multiplication of the production of the oxygen free radicals (Ziemba et al. 2005). The high bleaching effect resulted from Zoom 2 application might have left the enamel surface to be receptive to ACP application which penetrated the surface defects and filled the surface created porosities (Tezel et al. 2007). Also, the deposits of the remineralizing agent on the bleached enamel might have performed as a physical obstacle to limit the connection of the enamel to the acid to provide an additional mineral that must be dissolved during the acidic challenge before the underlying enamel is attacked (Attin et al. 2005). These results were in an agreement with (Geiger et al. 2003; and Tung and Eichmiller 2004). They reported that ACP could stabilize the calcium phosphate on the enamel surface, thus preserving the high concentration grades of the ions resulting in promoting hard tissue remineralization.

Although elemental analysis results revealed that the exposure of $25 \%$ hydrogen peroxide bleached enamel (Zoom 2 in-office bleaching (group B)) to the acid beverage did not showed significant $\mathrm{Ca}$ and $\mathrm{P}$ wt\% change compared to the control unbleached group (group A), SEM photomicrograph showed relativity smooth enamel surface with minor pores, with no visible evidence of etching and prism pattern appearance for Zoom 2 bleached specimens (Fig. 1b), which support the role of adding ACP by acting as a physical barrier protecting enamel from acid attack (Attin et al. 2005).

On the other hand, although Nite white bleaching agent incorporate ACP with the $22 \%$ carbamide peroxide gel together in the dual barrel syringe, after exposing to the erosive challenge enamel specimens bleached with Nite white bleaching agent observed a statistically significant reduction in both the $\mathrm{Ca}$ and $\mathrm{P}$ wt\% compared to the control with Zoom 2 bleached specimens.

The difference in the results in the present study between these two bleaching materials might be also due to the factors found to enhance ion release, such as: the duration of treatment, the composition and the $\mathrm{pH}$ of the bleaching agent (Rotstein et al. 2004).

Zoom 2 consists of $25 \%$ hydrogen peroxide gel which was photo-activated and was applied in a total of $45 \mathrm{~min}$ 
treatment. On the other hand, Nite White ACP was athome chemically-activated bleaching gel consisting of $22 \%$ carbamide peroxide material and was applied one hour daily for two weeks resulting in a total of $14 \mathrm{~h}$ treatment. It is well known that carbamide peroxide undergoes dissociation forming urea and hydrogen. Peroxide are able to disperse through enamel due to its decreased molecular weight. Hydrogen peroxide breaks down into water and oxygen; urea breaks down into carbon dioxide and ammonia. As urea is a by-product of such bleaching agents, possibility of fading the tooth structure could be involved. The presence of urea caused losing the enamel proteins and other correlated minerals, attacking the core or intra-prismatic area and generating porosities at the surfaces (Magalbaes et al. 2008; Moraes et al. 2006). This was supported by the SEM photomicrograph of Nite White ACP specimens (Fig. 1c) which showed removal of the aprismatic layer, increased depth of enamel grooves, and irregular depressions of various depths. This could be correlated to the significant reduction in the $\mathrm{Ca}$ and $\mathrm{P}$ ions after carbamide peroxide bleaching that could resulted in morphological variations in the superficial enamel.

Moreover, the $\mathrm{pH}$ of Nite white ACP bleaching gel $(\mathrm{pH}=5.5)$ is more acidic compared to Zoom 2 bleaching gel $(\mathrm{pH}=7-9)$. The longer application time of Nite White and its low $\mathrm{pH}$ value, might also explain the significant decrease in $\mathrm{Ca}, \mathrm{P}$ wt\% which indicates the more dissolutive impact of this bleaching material on the enamel surface. In addition, the acidity of Nite White bleaching agent might have caused breaking down of the incorporating $\mathrm{ACP}$, causing it to be delivered into the enamel tooth surface in a non-active form. It was stated that application of remineralizing agent following bleaching treatment might increase the enamel resistance against the erosive attacks compared to only bleached enamel without remineralization. However, adding that remineralizing agent to the bleaching gel might result in a limited protection compared to remineralizing alone after bleaching treatment since the bleaching lowered the remineralizing agent uptake by the bleached surface (Attin et al. 2003).

Enamel is composed mainly of inorganic materials: calcium and phosphate ions make approximately $95 \%$ to $98 \%$ of hydroxyapatite crystals. However, these are not pure crystals, as they are carbonated and have residue minerals as potassium, sodium, and magnesium. These elements make biological hydroxyapatite more soluble than pure hydroxyapatite (Abou Neel et al. 2016).

In the current study after exposure to the acidic challenge, $\mathrm{Na}$ wt \% was least in Nite white incorporating $\mathrm{ACP}$, followed to the control group, then Zoom 2 followed with ACP application, with statistically significant difference between them. Moreover, there was non statistically significant decrease in $\mathrm{Mg}$ wt\% between the three tested groups. Loss of $\mathrm{Na}$ and $\mathrm{Mg}$ from enamel are also indicative to loss of mineralized tissue which was coherent with previous studies findings (Borges et al. 2011; Coceska et al. 2015). Mg loss might be due to the fact that $\mathrm{Mg}$ ion is from the first element that could be dissolved throughout the demineralization process; so loss of $\mathrm{Mg}$ could be considered as an initial sign of demineralization (Borges et al. 2011).

Finally, in the current study the first null hypothesis that both in-office and at-home bleaching agents did not rise the enamel liability to erosive challenges, was accepted only for Zoom 2 in-office bleaching agent, as Nite white ACP at-home bleaching increased the enamel susceptibility to erosive challenges.

While regarding the second null hypothesis that there was no difference in the erosion vulnerability of the enamel after being treated by an in-office bleaching agent followed by ACP application in a separate step, compared to enamel treated with at-home bleaching agent with ACP incorporated in its formula was rejected.

\section{Conclusion}

Under the conditions of the present study it could be concluded that:

- Enamel susceptibility to acidic challenge following bleaching procedure was material dependent.

- In-office Zoom 2 bleaching gel followed by ACP application didn't increase enamel susceptibility to acidic challenge.

- Adding ACP to the composition of Nite white bleaching gel had no beneficial effect on decreasing enamel susceptibility to acidic challenge.

\section{Abbreviations}

ACP: Amorphous calcium phosphate; Ca: Calcium; P: Phosphorus; Na: Sodium; Mg: Magnesium.

\section{Acknowledgements}

Not applicable.

\section{Authors' contributions}

SMN and SHN performed the study design, prepared the specimens and performed the whole methodology in the study and analyzed the data. SMN and SHN were the major contributors in writing the manuscript. MZ revised the manuscript. All the authors read and approved the final manuscript.

\section{Funding}

This research did not receive any specific grant from backing supports in the public, commercial, or not-for-profit sectors. 


\section{Availability of data and materials}

The authors announce that the data supporting the results of this study are existing within the article.

\section{Declarations}

\section{Ethics approval and consent to participate}

Not applicable.

\section{Consent for publication.}

Not applicable.

\section{Competing interests}

No competing interests.

\section{Author details}

${ }^{1}$ Restorative and Dental Materials Department, Oral and Dental Research Division, National Research Centre, 33 El Bohouth st. (former El Tahrir st.), P.O.12622, Dokki, Giza, Egypt. ${ }^{2}$ Restorative and Dental Materials Department, Head of Oral and Dental Research Division, National Research Centre, Cairo, Egypt.

Received: 12 February 2021 Accepted: 15 March 2021

Published online: 25 March 2021

\section{References}

Abou Neel EA, Aljabo A, Strange A, Ibrahim S, Coathup M, Young AM (2016) Demineralization-remineralization dynamics in teeth and bone. Int J Nanomed 11:4743-4763

Attin T, Albrecht K, Becker K, Hannig C, Wiegand A (2005) Influence of carbamide peroxide on enamel fluoride uptake. J Dent 34:668-675

Attin T, Kocabiyi K, Buchalla W, Hannig C, Becker K (2003) Susceptibility of enamel surfaces to demineralization after application of fluoridated carbamide peroxide gels. Caries Res 37:93-99

Borges BCD, Borges JS, De Melo CD (2011) Efficacy of a novel at-home bleaching technique with carbamide peroxides modified by cpp-acp and its effect on the microhardness of bleached enamel. Oper Dent 36:521-528

Cakir FY, Oztas SS, Firat E (2012) Effect of office bleaching systems on chemical compositions of enamel and dentin: an in vitro study. Clin Dent Res 36:35-41

Chen HP, Chang CH, Liu JK, Chuang SF, Yang JY (2008) Effect of fluoride containing bleaching agents on the enamel surface properties. J Dent 36:718-725

Chuang SF, Chen HP, Chang CH, Liu JK (2009) Effect of fluoridated carbamide peroxide gels on enamel micro-tensile bond strength. Euro J Oral sci 117:435-441

Coceska E, Gjorgievska E, Coleman NJ, Gabric D, Slipper IJ, Anovic MS (2015) Enamel alteration following tooth bleaching and remineralization. J Microsc 00:1-13

De Vasconcelos AAM, Cunha AGG, Borges BCD, Vitoriano JDO, Junior CA, Machado CT (2012) Enamel properties after tooth bleaching with hydrogen/carbamide peroxides in association with a CPP-ACP paste. Acta Odontol Scand 70:337-343

Elfallah HM, Swain MV (2013) A review of the effect of vital teeth bleaching on the mechanical properties of tooth enamel. N Z Dent J 109:87-96

Engle K, Hara AT, Matris B, Eckert J, Zero DT (2010) Erosion and abrasion of enamel and dentin associated with at-home bleaching. J Am Dent Assoc 141:546-551
Geiger S, Matalon S, Blasbag J, Tung MS, Eichmiller FC (2003) The clinical effect of amorphous calcium phosphate (ACP) on root surface hypersensitivity. Oper Dent 28:496-500

Giannini M (2013) Color alteration and hydrogen peroxide decomposition of high-concentrated bleaching agents on enamel. Dent Mater 1:37-46

Hegedus C, Bistey T, Flora-Nagy E, Keszthelyi G, Jenei A (1999) An atomic force microscopy study on the effect of bleaching agents on enamel surface. J Dent 27:509-515

Magalhaes AC, Stancari FH, Rios D, Buzalaf MAR (2007) Effect of an experimental $4 \%$ titanium tetra fluoride varnish on dental erosion by a soft drink. J Dent 35:858-861

Mielezarek A, Klukowska M, Ganowiez M, Kwiatkowska A, Kwasny M (2008) The effect of strip, tray and office peroxide bleaching systems on enamel surfaces in vivo. Dent Mater 24:1495-1500

Moraes RR, Marimon JL, Schneider LF, Correr Sobrinho L, Camacho GB (2006) Carbamide peroxide bleaching agents: effects on surface roughness of enamel, composite and porcelain. Clin Oral Investig 10:23-28

Moreira RF, Santos FP, Santos EA, Dos Santos RS, Dos Anjos MJ, De Miranda MS (2017) Analysis of the chemical modification of dental enamel submitted to $35 \%$ hydrogen peroxide "In-office"Whitening with or without calcium. Int J Dent Article ID 4646789:1-5

Oldonini G, Bruno A, Genoves AM, Parisi L (2018) Effects of ACP administration on dental sensitivity during in-office and at-home interventions. Dent J $6: 1-8$

Pashley DH, Tay FR, Yiu CKY, Hashimoto M, Breschi L, Carvalho R, Ito S (2004) Collagen degradation by host derived-enzymes during aging. J Dent res $83: 216-221$

Poggio C, Grasso N, Ceci M, Betrami R, Colombo M, Chiesa M (2016) Ultrastructural evaluation of enamel surface morphology after tooth bleaching followed by the application of protective pastes. Wiley Periodicals 38:221-226

Poomi S, Kumar RA, Shankar P, Indira R, Ramachandran S (2010) Effect of $10 \%$ sodium ascorbate on the ca:p ratio of enamel bleached with 35\% hydrogen peroxide: an in vitro quantitative enamel-dentin $x$-ray analysis. Contemp Clin Dent 1:223-226

Rotstein I, Avron Y, Shemesh H, Dogan H, Mor C, Steinberg D (2004) Factors affecting mercury release from dental amalgam exposed to carbamide peroxide bleaching agent. Am J Dent 17:347-350

Santini A, Pulham CR, Rajab A, Ibbetson R (2008) Effect of a 10\% carbamide peroxide bleaching agent on the phosphate concentration of tooth enamel assessed by raman spectroscopy. Dent Traumatol 24:220-223

Tezel H, Ertas OS, Ozata F, Dalgar H, Korkut ZO (2007) Effect of bleaching agents on calcium loss from enamel surface. Quintessence Int 38:339-347

Tung MS, Eichmiller FC (2004) Amorphous calcium phosphates for tooth mineralization. Compend 25:9-13

Whang HJ, Shin DH (2015) Effects of applying antioxidants on bond strength of bleached bovine dentin. Restor Dent Endod 40:37-43

Yamaguchi K, Miyazaki M, Takamizawa T, Inage H, Moore K (2006) Effect of CCP-ACP paste on mechanical properties of bovine enamel as determined by an ultrasonic device. J Dent 34:230-236

Ziemba SL, Felix H, Macdonald J (2005) Clinical evaluation of a novel dental whitening lamp and light-analyzed peroxide gel. J Clin Dent 16:123-127

\section{Publisher's Note}

Springer Nature remains neutral with regard to jurisdictional claims in published maps and institutional affiliations. 